\title{
Human uncoupling protein-3 and obesity: an update
}

Citation for published version (APA):

Hesselink, M. K. C., Mensink, M. R., \& Schrauwen, P. (2003). Human uncoupling protein-3 and obesity: an update. Obesity Research, 11(12), 1429-1443. https://doi.org/10.1038/oby.2003.192

Document status and date:

Published: 01/01/2003

DOI:

10.1038/oby.2003.192

Document Version:

Publisher's PDF, also known as Version of record

Document license:

Taverne

\section{Please check the document version of this publication:}

- A submitted manuscript is the version of the article upon submission and before peer-review. There can be important differences between the submitted version and the official published version of record.

People interested in the research are advised to contact the author for the final version of the publication, or visit the DOI to the publisher's website.

- The final author version and the galley proof are versions of the publication after peer review.

- The final published version features the final layout of the paper including the volume, issue and page numbers.

Link to publication

\footnotetext{
General rights rights.

- You may freely distribute the URL identifying the publication in the public portal. please follow below link for the End User Agreement:

www.umlib.nl/taverne-license

Take down policy

If you believe that this document breaches copyright please contact us at:

repository@maastrichtuniversity.nl

providing details and we will investigate your claim.
}

Copyright and moral rights for the publications made accessible in the public portal are retained by the authors and/or other copyright owners and it is a condition of accessing publications that users recognise and abide by the legal requirements associated with these

- Users may download and print one copy of any publication from the public portal for the purpose of private study or research.

- You may not further distribute the material or use it for any profit-making activity or commercial gain

If the publication is distributed under the terms of Article $25 \mathrm{fa}$ of the Dutch Copyright Act, indicated by the "Taverne" license above, 


\title{
Review
}

\section{Human Uncoupling Protein-3 and Obesity: An Update}

\author{
Matthijs K.C. Hesselink, * Marco Mensink, $\dagger$ and Patrick Schrauwen $\dagger$
}

\begin{abstract}
HESSELINK, MATTHIJS K.C., MARCO MENSINK, AND PATRICK SCHRAUWEN. Human uncoupling protein-3 and obesity: an update. Obes Res. 2003;11: $1429-1443$.

The cloning of the uncoupling protein (UCP) 1 homologs $\mathrm{UCP} 2$ and UCP3 has raised considerable interest in the mechanism. The expression of UCP3 mainly in skeletal muscle mitochondria and the potency of the skeletal muscle as a thermogenic organ made UCP3 an attractive target for studies toward manipulation of energy expenditure to fight disorders such as obesity and type 2 diabetes. Overexpressing UCP3 in mice resulted in lean, hyperphagic mice. However, the lack of an apparent phenotype in mice lacking UCP3 triggered the search for alternative functions of UCP3. The observation that fatty acid levels significantly affect UCP3 expression has given UCP3 a position in fatty acid handling and/or oxidation. Emerging data indicate that the primary physiological role of UCP3 may be the mitochondrial handling of fatty acids rather than the regulation of energy expenditure through thermogenesis. It has been proposed that UCP3 functions to export fatty acid anions away from the mitochondrial matrix. In doing so, fatty acids are exchanged with protons, explaining the uncoupling activity of UCP3. The exported fatty acid anions may originate from hydrolysis of fatty acid esters by a mitochondrial thioesterase, or they may have entered the mitochondria as nonesterified fatty acids by incorporating into and flipflopping across the mitochondrial inner membrane. Regardless of the origin of the fatty acid anions, this putative function of UCP3 might be of great importance in protecting mitochondria against fatty acid accumulation and may help to maintain muscular fat oxidative capacity.
\end{abstract}

Received for review June 3, 2003.

Accepted in final form October 3, 2003.

*Department of Movement Sciences and †Department of Human Biology, Nutrition and Toxicology Research Institute Maastricht, Maastricht University, Maastricht, The Netherlands.

Address correspondence to Matthijs K.C. Hesselink, Department of Movement Sciences, Maastricht University, PO Box 616, 6200 MD Maastricht, The Netherlands.

E-mail: matthijs.hesselink@bw.unimaas.nl

Copyright () 2003 NAASO
Key words: uncoupling protein 3, fatty acid metabolism, energy expenditure, reactive oxygen species, lipotoxicity

\section{Introduction}

In all living systems, combustion of nutrients to carbon dioxide and water is the main pathway for releasing the energy needed to fuel cellular processes like ion pumping, muscular contraction, protein synthesis, and degradation of nutrients in the digestive tract. In all these processes, hydrolysis of adenosine triphosphate (ATP) ${ }^{1}$ the universal phosphor donor, liberates the energy needed. Therefore, it is of utmost importance that ATP levels are maintained, even under conditions of severe energy stress. The vast majority of ATP is synthesized in a process referred to as mitochondrial oxidative phosphorylation. Degradation of nutrients like proteins, carbohydrates, and lipids ultimately results in the production of the co-enzymes nicotinamide adenine dinucleotide and flavin adenine dinucleotide, which can, in turn, be oxidized to nicotinamide adenine dinucleotide $\left(\mathrm{NAD}^{+}\right)$and flavin adenine dinucleotide and $\mathrm{H}^{+}$in exchange for an electron. This process, referred to as the electron transfer or respiratory chain, is located in the inner mitochondrial membrane. According to the chemiosmotic theory defined by Mitchell and Moyle (1), the electron transfer chain results in a net proton gradient across the inner mitochondrial membrane. If the proton gradient is high enough, the protons may flow back to the mitochondrial matrix through the $\mathrm{F}_{0}-\mathrm{F}_{1}$-ATPase, releasing the energy needed to phosphorylate adenosine diphosphate (ADP) and generate ATP (oxidative phosphorylation). In tightly coupled mitochondria, there is no proton leak across the inner mitochondrial membrane, and all the energy built up in the respiratory chain can be used for (is coupled to) generation of ATP.

\footnotetext{
${ }^{1}$ Nonstandard abbreviations: ATP, adenosine triphosphate; ADP, adenosine diphosphate BAT, brown adipose tissue; UCP, uncoupling protein; GDP, guanosine diphosphate hUCP3, human uncoupling protein-3; ROS, reactive oxygen species; FFA, free fatty acid ${ }^{31} \mathrm{P}-\mathrm{NMR},{ }^{31} \mathrm{P}$-labeled nuclear magnetic resonance; TCA, tricarboxylic acid; acylCoA, acyl-coenzyme A; CAT, carnitine acyltransferase; MTE1, mitochondrial thioesterase; PPAR, peroxisome proliferator-activated receptor.
} 


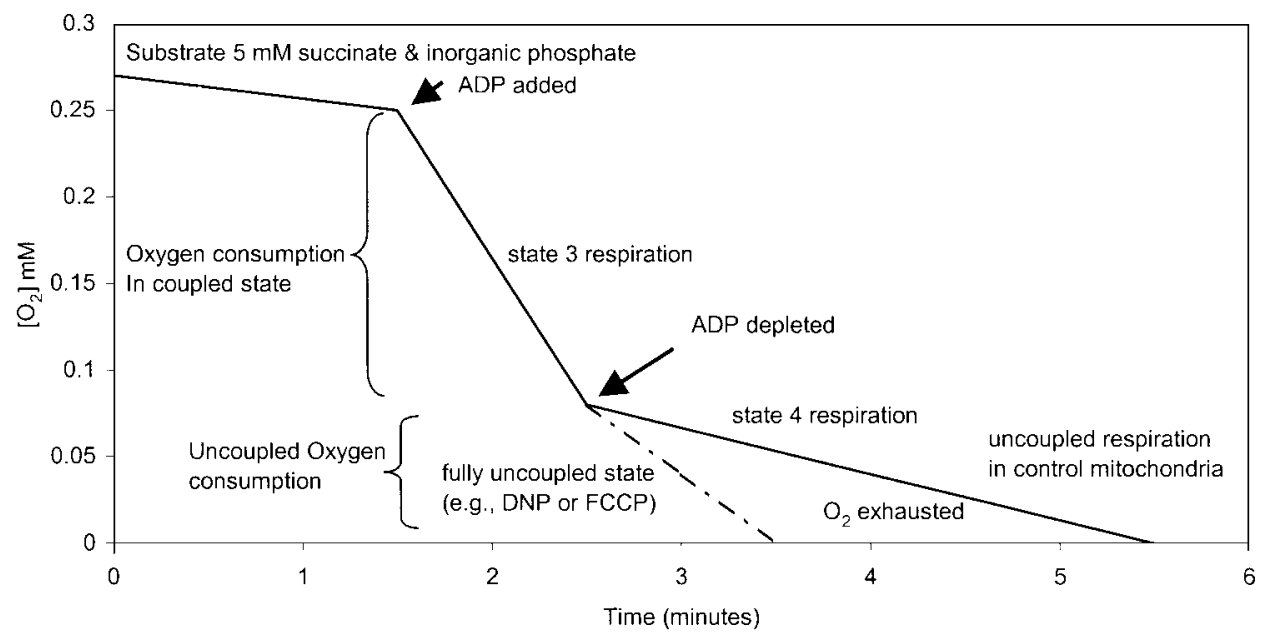

Figure 1: Typical recording of oxygen uptake of mitochondria in vitro. In the presence of substrate, inorganic phosphate, and oxygen, with ATP hydrolysis blocked, mitochondria start respiring at a relatively high rate (state 3 respiration). Under state 3 conditions, oxygen is consumed and coupled to phosphorylation of ADP to ATP, which is driven by the energy liberated in the electron transfer chain (coupled respiration). On depletion of ADP (because all ADP has been phosphorylated and ATP hydrolysis is blocked), mitochondria continue respiration at a much lower rate, referred to as state 4 respiration. Because the energy generated in the electron transfer cannot be coupled to oxidative phosphorylation (because ADP is depleted), this is uncoupled respiration. If uncoupling agents like dinitrophenol (DNP) or $p$-trifluoromethoxy carbonyl cyanide phenyl hydrazone (FCCP) are added to the medium, the rate of uncoupled respiration is increased (fully uncoupled respiration), as indicated by the rapid depletion of oxygen from the medium (dotted line). Note that uncoupled respiration is an intrinsic trait of mitochondria (also of "normal healthy" mitochondria).

However, it has long been recognized that, even in the absence of ADP, isolated mitochondria do show respiration. Obviously, in this condition, the potential energy of the proton gradient is not used for phosphorylation of ADP, indicating that there is proton transfer across the inner mitochondrial membrane that is not coupled to phosphorylation of ADP (referred to as proton leak or mitochondrial uncoupling). This process, called state 4 respiration (Figure 1), indicates that uncoupling of mitochondria is an existing phenomenon that occurs in mitochondria derived from numerous tissues [e.g., brown adipose tissue (BAT), skeletal muscle, and hepatocytes]. For most tissues, the physiological significance of uncoupling is still unknown, but much is learned from the mitochondrial uncoupling that occurs in BAT. This tissue plays a recognized role in adaptive thermogenesis, when the energy generated in the electron transfer chain is released as heat rather than used for phosphorylation of ADP, thereby allowing adaptation to cold. Conversely, during hibernation, when preservation of energy is essential, BAT mitochondria become more tightly coupled, attenuating energy expenditure and saving energy stores. Moreover, only in BAT has the protein responsible for mitochondrial uncoupling been identified and named thermogenin [now called uncoupling protein-1 (UCP1)] (2). Thus, this protein is responsible for adaptive thermogenesis and, therefore, the regulation of energy balance in rodents.

As the amount of BAT in adult humans is scarce, it could be argued that proton leak and its concomitant increase in basal metabolic rate are trivial processes in adult humans. It should be noted, however, that computations have been made indicating that in vivo proton leak in liver and skeletal muscle mitochondria may account for $\sim 20 \%$ of the basal metabolic rate (3). In addition to this, it was shown that in contracting skeletal muscle, proton leak makes up $15 \%$ of basal metabolic rate (4). Whereas these studies clearly underscore the impact of proton leak on basal metabolic rate, the protein(s) responsible for the proton leak had not been identified. Not surprisingly, the discovery of the UCP1 homologs UCP2 (5) and UCP3 (6) in 1997 was warmly welcomed.

The ubiquitous expression of UCP2, the expression of UCP3 in skeletal muscle, and their homology with the "true" (7) uncoupling protein UCP1 made UCP2 and UCP3 attractive targets for interventions aimed at manipulating energy expenditure. Extensive research toward the regulation and the putative functions of these novel uncoupling proteins has resulted in a vast amount of publications in the last 6 years. Notwithstanding the overwhelming number of studies published, there seems to be no consensus on a possible role for these novel uncoupling proteins in the regulation of energy expenditure and obesity. In fact, the primary function of UCP2 and UCP3 is still under debate. Because UCP3 is expressed almost exclusively in skeletal muscle, which makes up $\sim 40 \%$ of the body mass in lean individuals and is responsible for the majority of the basal metabolic rate, the pioneering studies focused mainly on 
UCP3 and its putative role in energy expenditure. Here we aim to review the literature currently available on UCP3 in relation to its regulation and function and the implications for obesity.

\section{Expression of UCP3 in Cell Systems}

Based on the similarity of the amino acid sequences of UCP3 and UCP1 [57\%; (6)], suggestions were made that UCP3 may possess uncoupling activity in vivo. Indeed, it was shown that expression of recombinant human UCP3 in yeast lowered the mitochondrial membrane potential (8), increased basal oxygen consumption by $31 \%$, induced a $20 \%$ increase in state 4 respiration in isolated mitochondria, and retarded growth (9). It was also shown that overexpressing UCP3 in yeast induced a decline in cellular respiration coupled to oxidative phosphorylation from $57 \%$ to $11 \%$; this decline was concerted with a $33 \%$ increase in cellular heat production (10). These findings seem to confirm uncoupling activity of UCP3 in vitro. However, it was also noted that, in a heterologous yeast expression system, the uncoupling activity of UCP3 was hardly affected by guanosine diphosphate (GDP) or ATP (11), which was expected based on the similarity of UCP3 with UCP1.

Although the pioneering studies of (over)expression of UCP3 in cell systems have certainly been valuable, these studies have also been criticized (12). The main criticism relates to computation of the respiratory control values (the ratio of fully uncoupled respiration over state 4 respiration, see Figure 1). Adding a chemical uncoupler to the incubation medium and measuring maximal respiration rates is referred to as fully uncoupled respiration. Thus, if UCP3 is considered a true uncoupler, it should increase state 4 respiration but leave the fully uncoupled state unaffected. However, the fully uncoupled respiration in in vitro UCP3 overexpression conditions was lower compared with control values. These results can be interpreted as a malfunctioning of the electron transfer chain (12). Interestingly, it was shown that yeast overexpressing UCP1 at modest concentrations possessed the expected uncoupling behavior (i.e., GDP inhibitable uncoupling and unaffected rates of the fully uncoupled state), whereas yeast overexpressing UCP1 at higher concentrations were growth retarded, partly GDP insensitive, and had decreased chemically uncoupled respiration (13). These observations are similar to UCP3-expressing yeast and may indicate that expression of UCP3 in yeast induces artifactual uncoupling, possibly induced by improper incorporation of UCP3 in the inner mitochondrial membrane. With respect to this, it is important to note that it was shown that after sonication and differential centrifugation, UCP3 and its degradation products were primarily present in extramitochondrial fractions (14) rather than folded properly into the mitochondria.

In conclusion, yeast systems expressing UCP3 in vitro have taught us that UCP3 expression affects the mitochon- drial membrane potential, decreases chemically uncoupled respiration, and mildly increases state 4 respiration, and that the observed uncoupling cannot be inhibited by GDP or ATP, as in UCP1. Therefore, care should be taken when extrapolating these findings to in vivo (human) conditions.

\section{Is UCP3 a True Uncoupler?}

\section{UCP3 Overexpression}

Encouraging data that UCP3 might be a true uncoupler in vivo were reported by Clapham et al. (15), who showed that mice overexpressing UCP3 (UCP3-tg) were lean despite the fact that they are hyperphagic compared with their wildtype littermates. Additional phenotypical changes, next to the 66-fold up-regulation of UCP3 mRNA in skeletal muscle, include $25 \%$ increase in resting oxygen consumption, decreased fasting blood glucose and insulin levels, improved glucose tolerance, decreased total cholesterol, and a $44 \%$ to $57 \%$ reduction in adipose tissue over total animal volume. Shortly after this work, $\mathrm{Li}$ et al. overexpressed the BAT-specific UCP1 in skeletal muscle (by coupling UCP1 cDNA to a myosin light chain promoter) (16) and showed a similar phenotype (reduced body mass, decreased fasting blood glucose and triglycerides, and prevention of dietinduced obesity and insulin resistance). The straightforward interpretation of these data is that UCP3 overexpression results in increased energy expenditure and the accompanying phenotype. The results would suggest that UCP3 would be a good candidate for pharmaceutical up-regulation in the prevention and/or treatment of obesity. However, along the same lines as the overexpression of UCP3 in yeast was challenged (the lack of inducible uncoupling and the lack of inhibition by GDP), the increased proton leak and related phenotype in the UCP3-tg mice were considered artificial (17). Quantifying the absolute concentration of UCP3 in mitochondria isolated from UCP3-tg and wild-type mice (15) revealed that UCP3-tg mice had $\sim 22$-fold more UCP3 protein than age-paired wild-types (3200 vs. $140 \mathrm{ng} / \mathrm{mg}$ mitochondrial protein). According to Cadenas et al. (17), the uncoupling observed at this supraphysiological level of expression does not represent native uncoupling, because it cannot be induced by fatty acids or be inhibited by purine nucleotides as was shown for UCP3 expressed at physiological levels (18). The inability of overexpressed UCP3 to catalyze proton conductance was attributed to poor insertion or folding of UCP3 in the mitochondria, whereas the authors leave open the option that an unidentified endogenous cofactor is required to provoke UCP3 to affect proton conductance. However, no attempts have been made to examine if the protein was indeed poorly inserted or misfolded into the mitochondria in mice expressing supraphysiological levels of UCP3.

In an attempt to do so, we used immunogold electron microscopy to study the localization of human UCP3 

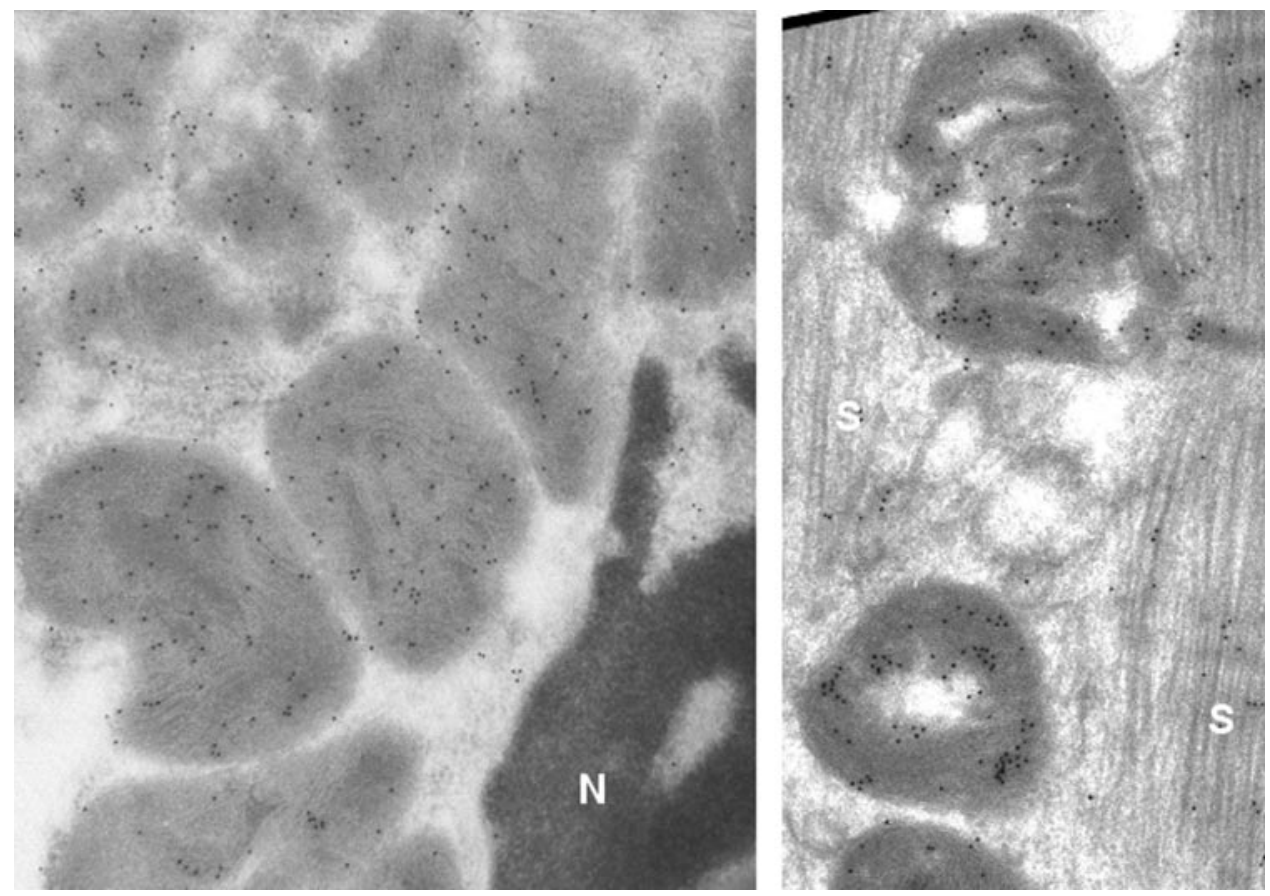

Figure 2: Immunogold electron microscopy staining of UCP3 in the medial gastrocnemius muscle of UCP3-tg mice. The left panel shows gold-labeled subsarcolemmal mitochondria, without staining in other subcellular constituents like the nuclei (n). The right panel shows gold-labeled intramyofibrillar mitochondria with sparse background labeling on sarcomeres (s). The antibody used was tested to specifically recognize human UCP3. Using this antibody, it was shown that, in UCP3-tg mice, the vast majority of the label was restricted to mitochondria.

(hUCP3) in the medial gastrocnemius muscle of mice overexpressing UCP3 (15). Similar to previous reports $(15,17)$, the UCP3-tg mice had lower body mass compared with wild-type littermates $(22.4 \pm 0.9$ vs. $25.9 \pm 0.8 \mathrm{~g}$, respectively) and a 5.8-fold higher UCP3 protein level. Using our previously validated antibody specifically detecting hUCP3 (code 1331) $(19,20)$, together with our antibody detecting both hUCP3 and endogenous mouse and rat UCP3 (code 1338), we were able to delineate hUCP3 expression from endogenous UCP3 expression in the UCP3-tg mice. It was shown that in wild-type mice only expressing endogenous UCP3, a clear mitochondrial labeling was observed with the mice-specific antibody (1338), whereas using the antihUCP3 (1331) antibody, no label was detected. In UCP3-tg mice, the vast majority of the label was associated with the inner mitochondrial membrane and the cristae and did not result in extramitochondrial labeling (Figure 2). This may indicate that artificial uncoupling in UCP3 overexpression systems, as suggested previously $(13,17,21)$, is not caused by extramitochondrial expression of UCP3. This is in contrast with observations in yeast, where it was shown that expression of UCP3 resulted in the majority of UCP3 present in extramitochondrial compartments (14). A major difference between UCP3 expression in yeast and in the UCP3-tg mice is the in vivo condition and, thus, the presence of all putative cofactors needed to induce or activate
UCP3. It should be noted, however, that our immunoelectron microscopical observations do not exclude that improper folding of UCP3 in the inner mitochondrial membrane resulted in pores in the inner membrane, thus leading to uncoupling in a way similar to protonophores (noninducible uncoupling). Moreover, the mice in our study showed a 5.8-fold up-regulation, which apparently is much lower than other data available on UCP3-tg mice at the protein level (17).

\section{UCP3 Ablation}

The generation of mice lacking the UCP3 gene (UCP3ko) by two independent groups $(22,23)$ has complicated matters. In these mice, decreased state 4 respiration with similar state 3 respiration levels have been reported (23), indicating more tightly coupled mitochondria. Whole body oxygen uptake and fuel partitioning (reflected by respiratory exchange ratio) under resting conditions were not affected in UCP3-ko mice $(22,23)$. Obviously, the lack of UCP3 was not compensated for by induction of any of the other uncoupling proteins known so far. The observation of more tightly coupled mitochondria in UCP3-ko mice did not result in apparent phenotypical changes $(22,23)$. By creation of a double knock-out, lacking UCP1 and UCP3, it was shown that the phenotype observed after deletion of the $U C P 1$ gene was not more pronounced by the additional 
deletion of UCP3 (22). Attempts to trigger a phenotype by exposing the UCP3-ko mice to a series of conditions previously related to induction of uncoupling proteins (high-fat feeding, cold exposure, stimulation with thyroid hormone) did not result in differences between the UCP3-ko and their wild-type littermates $(22,23)$, which was anticipated given the previous findings in mice overexpressing UCP3 (15). Interestingly however, Vidal-Puig et al. reported increased production of the superoxide anion in vitro and augmented mitochondrial aconitase production, indicating in vivo production of reactive oxygen species (ROS) in the UCP3-ko mice (23). These findings led the authors to suggest that one of the functions of UCP3 could be the prevention of excessive oxidative stress by lowering the mitochondrial membrane potential, thus lowering the probability for electrons to interact with oxygen (23).

In line with a role of UCP3 in prevention of oxidative stress, Echtay et al. suggested that for uncoupling proteins to induce uncoupling, both superoxides and coenzymeQ are obligatory factors (18). Indeed, it was shown that exogenous superoxide induced uncoupling in skeletal muscle mitochondria only in the presence of coenzymeQ, showing a 2-fold increase in uncoupling if UCP3 levels were doubled by fasting and a lack of effect of superoxide in mitochondria isolated from UCP3-ko mice (18). The increased uncoupling was inhibited by purine nucleotides, and the activation of uncoupling by superoxide was abolished if $0.3 \%$ bovine serum albumin was added to the medium and was restored by adding palmitic acid in the micromolar range (300 $\mu \mathrm{mol}$ ), indicating a role for free fatty acids (FFAs) in the activation of UCP3 (18). Although these studies clearly indicate that UCP3 can be involved in regulation of oxidative stress, one should keep in mind that the findings reported are derived from isolated mitochondria exposed to high levels of exogenous superoxide, which complicates extrapolation of these findings to intact humans. With respect to this, it is of relevance to note that the obligatory role of coenzymeQ in inducing uncoupling has recently been under debate; it was shown that after reconstitution of $\mathrm{UCP} 1,2$, and 3 in liposomes, the fatty acid catalyzed proton flux in these liposomes was unaffected by the presence of coenzymeQ (24). Rather, it was shown that the previously observed relevance of coenzymeQ in uncoupling was completely accounted for by the effect of its solvent dichloromethane (24).

In addition to in vitro measurements, an elegant, noninvasive in vivo ${ }^{31} \mathrm{P}$-labeled nuclear magnetic resonance $\left({ }^{31} \mathrm{P}\right.$ NMR) approach has been used to assess mitochondrial coupling in UCP3-ko mice. This approach revealed that the unidirectional rates of ATP synthesis were increased in UCP3-ko mice, whereas tricarboxylic acid (TCA) cycle flux remained unaltered (25). These findings were interpreted as evidence for uncoupling activity by UCP3 in vivo (25). It should be recognized, however, that increased ATP synthe- sis rate without alterations in TCA cycle flux is difficult to interpret, and simply interpreting it as increased coupling seems premature.

\section{Mitochondrial Uncoupling in Physiological Conditions Affecting UCP3}

In Pima Indians, sleeping metabolic rate is a very strong predictor of weight gain (26), and it was in this population that we reported significant correlations of UCP3 mRNA with both BMI (negative) and resting metabolic rate (positive) (27), suggesting that skeletal muscle UCP3 content is related to energy expenditure. In this context, it was already recognized that hyperthyroidism, characterized by increased energy expenditure, was associated with increased proton leak in liver mitochondria, whereas the opposite was observed in hypothyroidism (28). Interestingly, hypothyroid rats had only $32 \%$ of the UCP3 mRNA levels found in controls. Treatment of hypothyroid, but also euthyroid, rats with thyroid hormone induced a 4.7- and 6.2-fold increase in skeletal muscle UCP3 mRNA (8). These findings were extended with assessments of mitochondrial respiration rates in the transition from the hypothyroid to the euthyroid state, showing that state 3 and state 4 respiration rates were ranked hierarchically from hypothyroid $<$ euthyroid $<$ hyperthyroid (29), suggesting that UCP3 is involved in mediating the proton leak observed in hyperthyroidism. More compelling data for a role of UCP3 in thyroid hormoneinduced increases in energy expenditure are presented by de Lange et al. (30), showing that after a single dose injection of thyroid hormone, UCP3 mRNA peaked at 24 hours after injection. The increase in mRNA was reflected in increased protein levels 65 hours after injection, with a concerted increase in resting metabolic rate assessed in vivo (30).

Administration of thyroid hormone for 10 days in control rats resulted in an 8.1-fold increase in UCP3 mRNA, with concerted up-regulation of UCP3 at the protein level (2.8fold) (31). ${ }^{31} \mathrm{P}-\mathrm{NMR}$ spectroscopy revealed that the increase in UCP3 protein was associated with increased TCA cycle flux without an effect on unidirectional ATP synthesis rate; this was interpreted by the authors as a $60 \%$ decrease in mitochondrial coupling and has led them to suggest that $\mathrm{UCP} 3$ is responsible for the increased energy expenditure and thermogenesis observed after administration of thyroid hormone (31). In humans treated with thyroid hormone, similar changes in TCA cycle flux and unidirectional ATP synthesis rate were observed (32). Unfortunately, no UCP3 levels were reported in that study (32). It should, however, be noted that, although very elegant and noninvasive, results from ${ }^{31} \mathrm{P}$-NMR spectroscopy with regard to mitochondrial uncoupling have been nonuniformly interpreted; i.e., increased unidirectional ATP synthesis rate without effect on TCA cycle flux has been interpreted as decreased uncoupling (25), and, at the same time, increased TCA cycle flux without an effect on ATP synthesis rate has been taken as a 
marker for increased uncoupling $(31,32)$, whereas the combination of decreased TCA cycle flux with decreased ATP synthesis rate has been presented as a lack of effect on mitochondrial uncoupling (33). Thus, under pathophysiological conditions like hypo- or hyperthyroidism, UCP3mediated uncoupling cannot be excluded.

Another condition in which UCP3 protein levels are up-regulated is on consumption of high-fat diets. We recently showed that supplying subjects isocaloric high-fat vs. low-fat diets (60\% of energy as fat vs. $30 \%$ of energy as fat with identical protein levels) resulted in a significant increase in UCP3 protein levels within the physiological range within 7 days (34). After severe exhaustive ischemic contractile activity, mitochondrial coupling was measured in vivo by measuring creatine phosphate resynthesis rate after blood flow was reinstated. We concluded that, despite a $44 \%$ increase in UCP3 protein content and with all potential physiological modulators of UCP3 activity present, mitochondrial coupling was not affected (34), suggesting that mitochondrial uncoupling may not be the principal function of UCP3 in vivo.

\section{Summary}

To summarize, detailed examination of UCP3-tg and UCP3-ko mice has revealed that the observed phenotype of UCP3-tg mice, with characteristics apparently beneficial in the treatment of obesity, is most likely caused by uncoupling. Because the uncoupling in UCP3-tg mice is noninducible, it is considered artificial, possibly because of misfolded UCP3 and/or UCP3 loosely imported into the inner mitochondrial membrane. However, immunoelectron microscopy studies have shown that, in the UCP3-tg mice, almost all UCP3 expressed is confined to the mitochondria, in contrast to observations in yeast. The UCP3-ko mice lack an apparent phenotype, and reports on proton leak are inconsistent. These findings indicate that 1) the phenomenon uncoupling per se (inducible or noninducible) may be advantageous in the prevention or treatment of obesity; and 2) it is, however, unlikely that under physiological conditions, human UCP3 is a major contributor to the basal proton leak, possibly with an exception for T3-induced thermogenesis. Therefore, based on these studies, a role for UCP3 in energy metabolism would not be anticipated. Nevertheless, many studies have examined the effect of physiological interventions that alter energy metabolism on UCP3 expression to unravel the role of UCP3 in human physiology and possibly the regulation of body mass.

\section{UCP3 Expression under Physiological Conditions Affecting Energy Metabolism}

\section{Linkage and Association Studies}

Shortly after the discovery of the UCP3 gene, the genomic structure and chromosomal localization of hUCP3 were identified (35). It was shown that UCP3 was mapped within $7 \mathrm{~kb}$ of the $U C P 2$ gene on chromosome 11q13, a region that has been linked to obesity and hyperinsulinemia (5). Several polymorphisms in the UCP3 gene have been identified (36-42) and related to markers of energy metabolism and obesity. We have recently reviewed the effect of UCP3 polymorphisms known so far and concluded that the effect on markers of obesity shows inconsistent results (43).

Nonetheless, one of the early detected and promising observations was an exon 6-splice donor polymorphism, resulting in an apparent null mutation of $U C P 3$, reported in Gullah-speaking African Americans with early onset severe obesity (BMI $=38 \mathrm{~kg} / \mathrm{m}^{2}$ ) and type 2 diabetes (44). Interestingly, carriers of the exon 6-splice donor mutation had a significant ( $p=0.0188, n=24) 50 \%$ decrease in fat oxidation (44). It was this observation that tempted the authors to suggest that UCP3 may increase fat oxidation by introducing fatty acids into the mitochondrial matrix (44) and explain the declined fat oxidation in the carriers of the polymorphism. In later studies in African Americans (45) or in Danish whites (46), carriers of the exon 6-splice donor mutation showed no changes in resting metabolic rate or fuel partitioning.

Overall, the inconsistency in results linking UCP3 polymorphisms to obesity-related phenotypes does not favor a significant role for UCP3 in the regulation of energy expenditure, although a role of UCP3 in substrate metabolism in selected populations cannot be excluded.

\section{UCP3 Expression after $\beta$-Adrenergic Stimulation}

Another condition accompanied by increased thermogenesis is $\beta$-adrenergic stimulation. It was shown that ephedrine induced a $60 \%$ increase in oxygen consumption, and it was estimated that $\sim 50 \%$ of this increase was accounted for by muscular thermogenesis (47). Similar estimates of the contribution of skeletal muscle to adrenalin-induced increased energy expenditure were made (48). Given the skeletal muscle-specific expression of UCP3, it is tempting to relate the $\beta$-adrenergic increase in thermogenesis to UCP3.

Intraperitoneal injections with the $\beta 3$ adrenergic agonist CL-316243 in rats induced a prominent increase in UCP3 mRNA in white adipose tissue and, to a lesser extent, in skeletal muscle (8). Using the same compound, similar observations were made in obese rats treated for 10 days (49). This finding, however, could not be reproduced by others using trecadrine as a $\beta 3$-agonist (50). The observation in L6 myotubes that isoproterenol and salbutamol ( $\beta 2$ agonists) increased UCP3 mRNA levels, whereas propranolol (a $\beta 2$-antagonist) blunted the observed increase (51), suggests that UCP 3 may play a role in $\beta$-adrenergic activation-induced thermogenesis. However, observations of increases in UCP 3 after $\beta$-adrenergic stimulation are biased by increased lipolysis and a concomitant rise in FFA levels, 
known to induce UCP3 expression. To delineate the direct effect of $\beta$-stimulation from the effect of increased lipolysis on skeletal muscle UCP3 expression, we recently studied the effect of salbutamol infusion with and without acipimox (to block lipolysis) in humans. We found that salbutamol infusion did not increase UCP3 mRNA levels, but lowering FFA levels by blocking lipolysis with acipimox during salbutamol infusion resulted in a decrease in UCP3 mRNA (52). These results might imply that $\beta$-adrenergic stimulation does not affect UCP3 directly but rather indirectly by increasing FFA levels. Nevertheless, no studies have been performed that directly examine the effect of $\beta$-adrenergic stimulation on mitochondrial uncoupling, leaving the possibility open that uncoupling is involved in $\beta$-adrenergicinduced energy expenditure.

\section{Dietary Status, Plasma FFA Levels, and UCP3 Expression}

One of the early remarkable findings was that caloric restriction for 5 days resulted in a $\sim 2$ - to 3 -fold increase in UCP3 mRNA levels in lean and obese humans (53). In a study in rodents, it was shown that a 48-hour fast induced a 5.6-fold increase in UCP3 mRNA in the rat tibialis anterior muscle and that 24-hour fasting induced a 3.5-fold increase in UCP3 mRNA in the mouse soleus muscle without affecting basal heat production in vitro (54). These seemingly paradoxical observations, i.e., increased expression of UCP3 under conditions of attenuated energy expenditure, were put into perspective when plasma FFA levels were taken into consideration. Fatty acids have long been recognized as potent regulators of gene transcription for numerous genes. Indeed, it was shown that the 10 -fold increase in UCP3 in rats fasted for 24 to 72 hours could be mimicked by elevation of fatty acid levels (by infusion of Intralipid together with heparin; Pharmacia, Clayton, NC), whereas other physiological responses known to occur during fasting (a fall in leptin and increased corticosterone levels) had no effect on UCP3 mRNA (55). In addition, a fasting-induced (30 hour) increase in UCP3 mRNA was completely reversed within 2 hours of refeeding (56). The importance of fatty acids in induction of UCP3 is further illustrated by the observation that, in skeletal and heart muscle from fetal mice, UCP3 is not induced until lactation with high levels of fat, whereas a high-carbohydrate diet at weaning induces a decrease in UCP3 mRNA levels (57).

The effects of a fasting-induced increase in UCP3 on mitochondrial energy metabolism have been examined in control mice and UCP3-ablated mice. Again, fasting induced up-regulation of UCP3 mRNA in control mice but did not affect proton motive force and state 4 respiration (58). Interestingly, this was the first study to report increased respiratory exchange ratio values if UCP3-ko mice had ad libitum access to food compared with ad libitum-fed controls (58). Fasting attenuated these differences, albeit nonsignificantly. These observations were interpreted as supportive of the idea that UCP3 plays an important role in fat oxidation (58). Because subjects with decreased fat oxidative capacity are prone to developing obesity (59), the increased respiratory rate observed in UCP3-ablated mice could indicate that a complete lack of UCP3 may, in the long run, increase the propensity for obesity. With respect to this, it is of relevance to note that, in carriers of the exon 6-splice donor mutation, resulting in the absence of UCP3, conflicting data have been reported on respiratory exchange values.

Modifying nutritional status by feeding a high-fat diet has also been reported to profoundly affect UCP3 expression, as indicated, among others, by observations in weaning mice (60). In 5-week-old rats, UCP3 was induced on isocaloric high-fat feeding in gastrocnemius muscle and was reported to depend on both chain length of the fatty acids as well as on the extent of saturation (61). Feeding rats, ad libitum, a high-fat (60\% of energy from fat) vs. a low-fat diet (12\% of energy from fat) resulted in significant elevations in plasma FFA levels and induced a 2-fold increase in UCP3 protein level after 4 weeks of feeding, without affecting mitochondrial uncoupling or 24-hour energy expenditure (62). In humans, consumption of a high-fat diet by healthy, trained athletes for 4 weeks (41\% of energy from fat vs. 17\% of energy from fat) also resulted in increased UCP3 mRNA expression, with the most prominent results in humans with a high percentage of type IIa muscle fibers (63). In a recent study, feeding well-trained subjects high- and low-fat diets (65\% of energy from fat vs. $70 \%$ to $75 \%$ of energy as carbohydrate) for only 5 days in a crossover design did not affect $U C P 3$ gene expression, in contrast to other genes involved in lipid metabolism (64). The lack of effect of a high-fat diet on UCP3 may have been because of the relatively short period of high-fat consumption, possibly in combination with the selection of subjects recruited.

Together, these studies clearly indicate that increasing circulatory FFAs, either by fasting or by consumption of a high-fat diet, consistently results in induction of the UCP3 gene, with concordant changes in UCP3 protein content. This increase seems to depend on chain length and the extent of saturation of the fatty acids ingested. In none of the cases reporting increased UCP3 mRNA or protein levels was evidence found linking fatty acid-induced increased UCP3 to increased mitochondrial uncoupling. Thus, it seems that UCP3 does not play a major role in the prevention of high-fat diet-induced obesity.

\section{Acute and Frequent Physical Activity and UCP3 Expression}

Exercise, both acute and regular, plays an important role in the prevention of obesity, by enhancing either energy metabolism or fatty acid oxidation. Therefore, the effect of exercise on UCP3 regulation has been studied extensively. 
With regard to exercise, it is of importance to discern the effects of acute exercise from the effects of exercise training. There seems to be consistency with regard to the up-regulating effect of acute exercise on UCP3 levels. Two hours of treadmill running induced a $252 \%$ increase in UCP3 mRNA in white gastrocnemius and a $63 \%$ increase in red gastrocnemius (65). It has also been shown that the extent of increase in UCP3 depends on the duration of exercise; after only 30 minutes of exercise, UCP3 mRNA increased slightly, but significantly (66). When exercise was continued for 200 minutes, the induction in UCP3 was much more prominent, reaching levels of $\sim 700 \%$, with similar induction by either swimming exercise or treadmill running (66). In this study, increased mRNA matched almost perfectly with increased protein expression (66). In humans, 4 hours of cycling exercise induced an increase in transcriptional activity of UCP3 of almost $600 \%$ (67). The extent of increase was linked to the exercise duration, showing the most prominent induction after 4 hours of exercise (67).

A straightforward interpretation of this would be that exercise per se induces UCP3 transcription. If this would be the case, one would expect exercise training to result in increased UCP3 protein levels. Strikingly, rats housed for 9 weeks in cages equipped with running wheels, permitting increased spontaneous activity, had UCP3 levels similar to their sedentary counterparts (65). When subjected to an endurance training program of stepwise incremental load for 4 weeks followed by another 4 weeks at the same level of training volume and intensity, UCP3 was significantly down-regulated in soleus and anterior tibialis muscle, with the most prominent decrease in the latter (less oxidative) muscle (68). In endurance-trained humans, UCP3 mRNA levels were significantly lower compared with physically fit but untrained controls (maximal power output, 5.6 vs. 3.9 $\mathrm{W} / \mathrm{kg}$ body weight) (69). Subsequently, observations of decreased UCP3 mRNA in subjects after endurance training or in trained subjects were extended to the protein level $(70,71)$.

The complete absence of contractile activity after denervation results in a marked increase in UCP3 mRNA in rat skeletal muscle within 72 hours after cutting the sciatic nerve (65). Comparable observations were made in skeletal muscles of tetraplegic humans, showing increased UCP3 mRNA levels, which returned to control levels after an 8 -week training program of electrically stimulated cycling exercise (72).

The paradoxical increase of UCP3 mRNA after acute exercise and the decrement in UCP3 after exercise training or in endurance-trained athletes indicate that it is not exercise per se that affects UCP3 expression. To distinguish the effects of exercise as such from the exercise-induced increase in fatty acid levels, we monitored UCP3 mRNA expression before and 4 hours after a 2 -hour cycling exer- cise (73). Subjects were tested after an overnight fast and were given only plain water during and after exercise. This protocol resulted in substantial increases in plasma FFA levels, peaking to $1000 \mu \mathrm{M}$ immediately after cessation of exercise and remaining elevated during the 4-hour postexercise period ( $\sim 800$ to $900 \mu \mathrm{M})(73)$. In a second test, fatty acid levels were blunted by ingestion of glucose $(1.4 \mathrm{~g} / \mathrm{kg}$ body weight, in a $20 \%$ solution) before exercise and doses of $0.35 \mathrm{~g} / \mathrm{kg}$ body weight, in a $10 \%$ solution, during and after exercise. Glucose ingestion successfully suppressed lipolysis as indicated by the lack of effect of exercise on plasma FFAs and the decline in fat oxidation observed in the glucose trial (73). Under both conditions, subjects were able to maintain euglycemia throughout and after exercise. We showed that, only in the fasting trial, with very high levels of fatty acids present, UCP3 mRNA was increased 4 hours after exercise, whereas in the glucose condition, with no changes in fatty acid levels but with exercise of the same duration and work load, no effect on UCP3 mRNA was detected (73). Thus, we concluded that observations of increased UCP 3 mRNA after acute exercise are mediated by prolonged increased FFA levels and not by another factor intrinsically related to physical exercise.

Interestingly, Hildebrandt and Neufer (74) reported that 2 hours of treadmill running significantly attenuated the fasting-induced increase in the transcriptional rate of $U C P 3$, but not other genes related to lipid metabolism like lipoprotein lipase, long-chain acylCoA dehydrogenase, or carnitine palmitoyl transferase 1 (74). The authors suggested that fasting and exercise might trigger opposing regulatory mechanism(s) (74). This observation may indicate that it is not just FFA levels regulating UCP3 expression but that regulation of UCP3 expression is more delicate.

In summary, there seems to be consensus that acute exercise induces up-regulation of UCP3, most likely because of elevated plasma FFA levels. Interestingly, the study by Hildebrandt and Neufer (74) indicates that if fatty acid levels are increased at the onset of exercise, exercise may attenuate the increase in UCP3 mRNA. In this respect, it is important to note that initiation of exercise with elevated plasma FFA levels readily results in oxidation of fatty acids and consequently lower plasma fatty acid levels. This may indicate that the balance between fatty acid delivery to the cell and mitochondrial oxidation of fatty acids plays a crucial role in regulation of UCP3 expression. Along these lines, the decline in UCP3 content observed in trained individuals or after training can be explained by the training-induced increase in fat oxidative capacity. Indeed, we previously showed that UCP3 mRNA correlated negatively with maximal aerobic capacity (69). Although we are not aware of any studies aiming to examine the decrease in $\mathrm{UCP} 3$ in trained subjects in relation to mitochondrial coupling, indirect negative associations between UCP3 mRNA and mechanical efficiency point toward improved energy 
efficiency (69). It should be noted, however, that patients suffering from chronic respiratory disease have decreased mechanical efficiency (75) while having lower UCP3 protein content (76).

\section{From Regulation to Putative Physiological Function of UCP3}

\section{Clues from Studies Physiologically Manipulating UCP3}

As discussed above, several observations have been made suggesting that regulation of UCP3 is closely related to fatty acid metabolism. This has led to the suggestion that UCP3 is involved in the regulation of lipids as fuel substrate rather than as a mediator of regulatory thermogenesis (77). This suggestion was based, for the most part, on the tissuedependent differential mRNA expression of the UCP homologs in skeletal muscles of distinct fiber typology, which is consistent with the differential requirement of these tissues for lipids during fasting and their ability to shift from glucose to fat oxidation during refeeding and exercise. Thus, it was shown that increases in UCP3 mRNA, under conditions of elevated FFA levels, were more pronounced in muscles comprised of fibers enzymatically equipped for glycolysis (type IIa and IIx fibers) than in muscles made of slow (type I) fibers with a high fat oxidative capacity $(55,78)$. In addition, when examined at the cellular level, protein expression of UCP3 was most prominent in glycolytic type IIb (or type IIx) fibers, with somewhat lower expression in type IIa fibers and the lowest expression in the fat oxidative type I fibers, in healthy humans and type 2 diabetics $(20,70)$. Given the low expression of fat oxidative enzymes in type IIx fibers and the high level of UCP3 expression, it is not conceivable that UCP3 serves to facilitate fat oxidation. Also, decreased UCP3 content in skeletal muscle of endurance-trained athletes (70), known for their high fat oxidative capacity, does not favor the idea that UCP3 plays a major role in modulating fat oxidation. In fact, when lean, previously untrained subjects participated in a 3-month training program, their fat oxidative capacity increased significantly (79), whereas plasma FFA levels remained unaltered. Analyses of UCP3 protein content preand post-training revealed that training induced a decrease in UCP3. This decrease in UCP3 negatively correlated with the training-induced increase in fat oxidation; i.e., the subjects with the most prominent increase in fat oxidative capacity showed the most prominent decrease in UCP3 protein (71). The high capacity to oxidize fats in trained athletes may also be the reason for the observation that consumption of a high-fat diet for 5 days failed to affect UCP3 mRNA levels in athletes (64), whereas feeding a diet with comparable high levels of fat to normal healthy subjects (with normal fat oxidative capacity) for 7 days resulted in up-regulation of UCP3 at the protein level (34).

The reports referred to above indicate that increased fat oxidative capacity without marked increases in fatty acid supply induces down-regulation of UCP3 rather than upregulation, which was anticipated if the role of UCP3 was to modulate fat oxidation. Another model in which fat oxidative capacity is increased while plasma FFA levels are reduced is after weight reduction induced by caloric restriction for 10 weeks. Under these conditions, we have reported decreased UCP3 protein levels that correlated well with skeletal muscle fatty acid binding protein content (19). Interestingly, in obese patients $\left(\mathrm{BMI}=42 \mathrm{~kg} / \mathrm{m}^{2}\right)$ subjected to biliopancreatic diversion, a massive decrease in fat mass $(55 \%)$ was paralleled by significant reductions in UCP3 mRNA (45\%) and protein (35\%) (80). Thus, despite downregulation of UCP3, a massive reduction in body mass was observed, indicating that $\mathrm{UCP} 3$ plays no obligatory role in loss of body mass.

On the other hand, conditions in which UCP3 is upregulated are characterized by a rapid rise in fatty acid levels without improved fat oxidation capacity, such as fasting, acute exercise, and fatty acid infusion. In experimentally induced diabetes in rodents by administration of streptozotocin, fatty acid levels rise acutely without instantaneous effects on fat oxidative capacity. Indeed, increased UCP3 levels have been reported at the mRNA level after administration of streptozotocin $(81,82)$.

Altogether, the consistent conclusion of these studies is that UCP3 levels increase if there is an imbalance in fatty acid delivery and fat oxidation or, more precisely, if the supply of fatty acids to the mitochondria exceeds the capacity of the mitochondria to oxidize fatty acids.

\section{Deduction of the Principal Physiological Function of UCP3: A Hypothesis}

Oxidation of long-chain $(>\mathrm{C} 12)$ fatty acids starts with import of fatty acids into the mitochondria. To do so, the fatty acids need to cross the outer and the inner mitochondrial membrane. Whereas nonesterified (free) fatty acids can cross the outer mitochondrial membrane, transport across the inner mitochondrial membrane is more intricate. Transport across the inner mitochondrial membrane is, in general, facilitated by the carnitine acyltransferase system (CAT1 and CAT 2), which catalyzes the transport of fatty acyl-coenzyme A (acylCoA) esters. Outside the mitochondria, fatty acids are esterified by fatty acylCoA synthetase, resulting in fatty acylCoA, which, in turn, is converted into acylcarnitine by CAT1. Acylcarnitine crosses the inner mitochondrial membrane, where it is reconverted to fatty acylCoA by CAT2. Only in this form can fatty acids be degraded in the $\beta$-oxidation to acetylCoA, which, in turn, may enter the TCA cycle. Any defect in uptake through the carnitine acyltransferase system or downstream in $\beta$-oxidation will lead to decreased fat oxidation.

However, it has also been shown that transport of FFAs through phospholipid membranes occurs spontaneously when fatty acids are incorporated into the phospholipid 


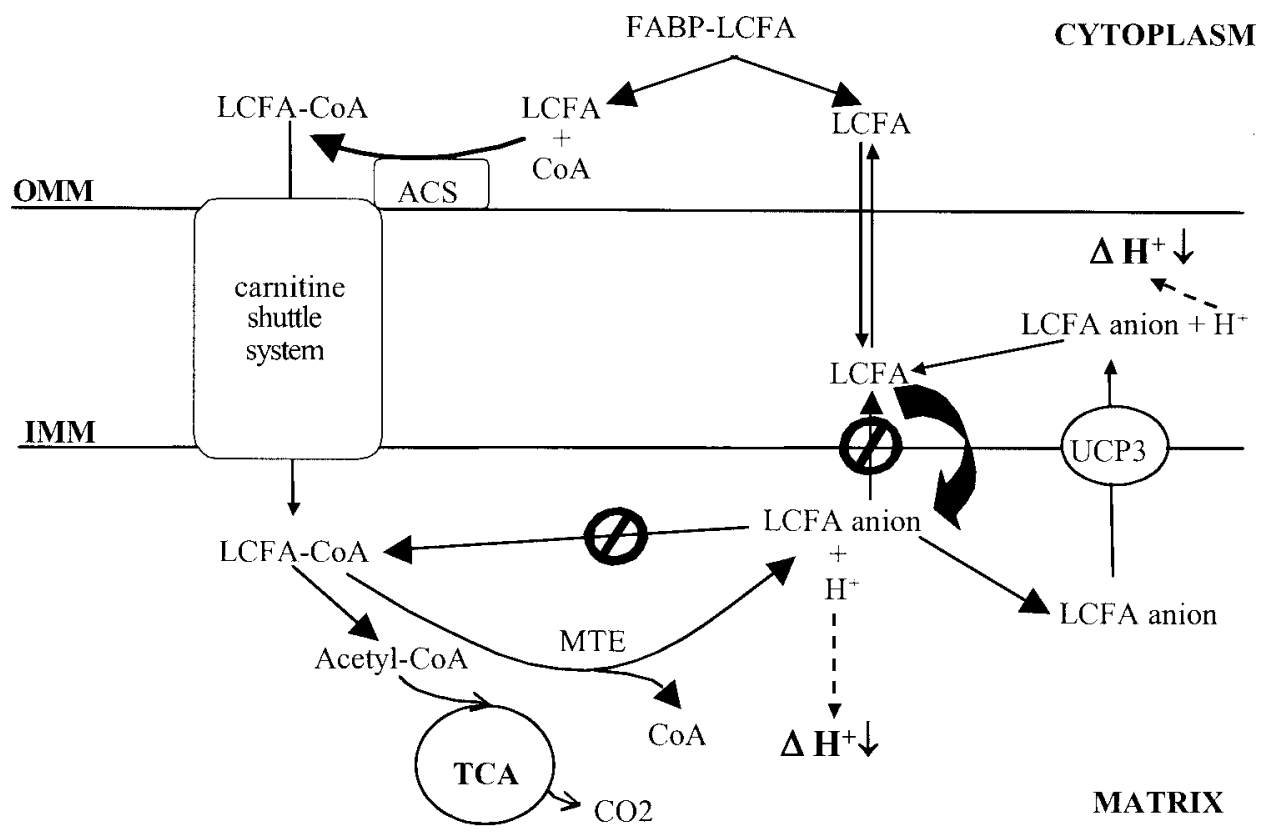

Figure 3: Schematic model of UCP3's putative function. UCP3 functions to export fatty acid anions from the mitochondrial matrix. These fatty acid anions might be derived either from entry of long-chain nonesterified fatty acids that entered the mitochondrial matrix by flip-flop across the mitochondrial innermembrane or by hydrolysis of fatty acid esters by an MTE1. Please note that by exporting fatty acid anions, UCP3 might still affect mitochondrial uncoupling. OMM, outer mitochondrial membrane; IMM, inner mitochondrial membrane; ACS, long-chain fatty acylCoA synthetase.

bilayer. Once incorporated, these fatty acids exist as both ionized and unionized species, and the unionized species crosses the membrane rapidly by flip-flop (83). In adipocytes, it was shown that entry of fatty acids occurred at high and low concentrations of fatty acids after kinetics of simple diffusion (83). This implies that if the load of fatty acids to the mitochondria is very high (e.g., after high-fat feeding, infusion of lipids, or acute exercise in the fasting state), a noteworthy portion of the fatty acids may enter the mitochondria through flip-flop in their nonesterified form. As fatty acids reach the mitochondrial matrix, they will be deprotonated because of the high $\mathrm{pH}$, accumulating nonesterified fatty acid anions within the mitochondrial matrix. Because mitochondria lack long-chain fatty acylCoA synthetase, these fatty acid anions cannot be esterified and, therefore, cannot be diverted toward $\beta$-oxidation; neither can they flip-flop back because of the proton gradient. Thus, prolonged exposure of mitochondria to fatty acids in levels high enough to exceed the oxidative capacity, either by limitations in the carnitine shuttle system or by defects more downstream, may result in redundant accumulation of fatty acid anions within the mitochondrial matrix. Here they may exert deleterious effects on mitochondrial function and may damage mitochondrial DNA. Mitochondrial DNA is more sensitive to damage than nuclear DNA and can be less efficiently repaired, underscoring the need to avoid the deleterious effects of increased levels of nonesterified fatty acid anions within the mitochondrial matrix. With respect to this hypothesis, it is of interest to note that UCP3 has been associated with a modulating role in oxidative stress by lowering production of ROS (23), thus lowering the risk of mitochondrial DNA damage. Because transport of fatty acid anions seems to be an accepted property of uncoupling proteins $(24,84,85)$, this has led us to hypothesize that UCP3 may function as a fatty acid anion exporter in exchange for a proton (Figure 3 ). Thus, UCP3 may primarily function as part of the mitochondrial defense mechanism against an excess load of fatty acids (71). It should be noted that by outward transport of fatty acid anions, the mitochondrial proton gradient is lowered and UCP3 might, as a consequence, possess mild uncoupling as a side effect.

Shortly after we submitted the paper describing this alternative role of UCP3 (71), a paper with a similar hypothesis was published (86). In this paper, Himms-Hagen and Harper propose that, once inside the mitochondrial matrix in their esterified form, not all fatty acylCoA esters are diverted toward $\beta$-oxidation, but that some may be hydrolyzed by a mitochondrial thioesterase (MTE1), resulting in fatty acids and coenzyme A. Again, because of the lack of fatty acylCoA synthetase within the mitochondrial matrix, outward transport of the fatty acid is preferred, and UCP3 is the protein hypothesized to be responsible. The authors suggest that the energy needed to esterify the fatty acids before entering the mitochondrial matrix (two ATP per fatty 
acid) may contribute to the increased energy expenditure observed in systems expressing UCP3 abundantly (86). This futile cycle may serve to liberate coenzyme A and regenerate the supply of coenzyme A-SH required for other metabolic processes within the mitochondria.

Regardless of the origin of the fatty acid anion within the matrix [either flip-flop of nonesterified fatty acid (originating in cytosol) across the inner mitochondrial membrane or by generation of nonesterified fatty acid by hydrolysis of fatty acylCoA by a mitochondrial thioesterase], both hypotheses propose that the primary role of UCP3 is the outward translocation of fatty acids away from the mitochondrial matrix. It should be noted that we hypothesize that fatty acid anion export is essential to prevent mitochondrial damage (e.g., by lipid peroxidation or damage to mitochondrial DNA), whereas Himms-Hagen and Harper propose that fatty acid anion export serves to liberate CoASH required for other metabolic processes.

\section{Testing the Feasibility that UCP3 is a Mitochondrial Fatty Acid Anion Exporter}

\section{UCP3 and MTE1 Are Regulated Concordantly}

The observation that mice overexpressing UCP3 possessed increased levels of MTE1 (87) was interpreted by Himms-Hagen and Harper as support for their hypothesis that UCP3 is an outward translocator of fatty acids generated by MTE1. As the levels of UCP3 expression in the UCP3-tg mice greatly exceed physiological levels, the authors extended their findings in obese and insulin-resistant $(d b / d b)$ mice and in their lean nondiabetic controls with endogenous UCP3 expression. In these mice, selective agonists of peroxisome proliferator-activated receptors (PPAR) $\alpha$ and $\gamma$ (Wy-14.643 and rosiglitazone, respectively) were used to affect UCP3 gene expression (88). Interestingly, under basal conditions, $d b / d b$ mice had increased skeletal muscle levels of UCP3 and MTE1 compared with their controls (88). If treated with rosiglitazone or the Wycompound, UCP3 and MTE1 were concordantly decreased compared with nondiabetic controls. The authors concluded that if changes in UCP3 mRNA occurred, these were complementary with changes in MTE1, suggesting that they are involved in the same metabolic pathway, either in response to, or as regulators of, fatty acid oxidation (88).

The above-mentioned studies clearly indicate that UCP3 and MTE1 are transactivated under the experimental conditions described. It should be noted, however, that in both experiments in which endogenous UCP3 was induced $(88,89)$, this was achieved by treatment with agonists of either PPAR $\alpha$ and/or PPAR $\gamma$. Both UCP3 $(90,91)$ and MTE1 (92) have PPAR responsive elements. Thus, the observed concerted up-regulation of UCP3 and MTE1 may reflect their PPAR responsiveness rather than a functional coupling between the two genes.
Clearly, the concordant response of UCP3 and MTE1 is an intriguing observation, compatible with a role of UCP3 as a fatty acid anion exporter. Detailed examination to elucidate if the transactivation of MTE1 and UCP3 also occurs in humans and after nonpharmaceutical induction of the $U C P 3$ gene is required.

\section{Manipulation of the Balance of Fat Supply and Fat Oxidation in Relation to UCP3 Expression}

To examine if UCP3 increases if the supply of nonesterified fatty acids to the mitochondria is increased and, thus, to test the feasibility that UCP3 could act as a fatty acid anion exporter, we blocked mitochondrial entry of fatty acids through CAT1 by administering Etomoxir (HPO Wolf, Projekt Entwicklung GmbH, Allensbach, Germany) for 36 hours to human subjects while they were consuming high-fat diets (to increase fatty acid supply). As a consequence, the concentration of sarcoplasmic FFAs will rise, and the fraction of fatty acids entering the mitochondria in their nonesterified form increases. Using respiration chambers, we showed that Etomoxir effectively interfered with fat oxidation, given the decreased fat and increased carbohydrate oxidation (93). In all subjects, UCP3 levels were increased after Etomoxir treatment compared with controls, resulting in an average increase of $67 \%$ at the UCP3 protein level after 36 hours! Furthermore, we observed a negative correlation between the decrease in fat oxidation after Etomoxir treatment and the increase in UCP3 protein (93). These data are highly compatible with our hypothesis that UCP3 exports fatty acid anions derived from "flip-flop"driven entry of nonesterified fatty acids. In addition, it should be noted that blockade of CAT1 is an experimental condition in which the entry of fatty acylCoA into the mitochondria is reduced, making it unlikely that the induction of UCP3 was related to the action of MTE1.

In addition to manipulation of fatty acid delivery to the mitochondria, we studied the effect of defective fat oxidative capacity. In rats rendered diabetic by treatment of streptozotocin, decreased fatty acid oxidative capacity was associated with increased UCP3 mRNA levels in the heart (81). Under healthy conditions, the heart relies almost exclusively on fat oxidation and is well equipped to efficiently handle lipids over a wide range of conditions. When thinking of UCP3 as a mitochondrial fatty acid anion exporter, it is not striking that UCP3 has been reported only at very modest protein levels in cardiac muscle. We recently confirmed the results of Hidaka et al. (81), showing a significant and massive increase in UCP3 mRNA and protein expression, which was closely associated with increased cytosolic fatty acids in the hearts of streptozotocin-treated rats (van der Vusse et al., unpublished data). This observation directly links the change in UCP3 to the change in sarcoplasmic nonesterified fatty acids. 
Alterations in fat oxidative capacity will also be reflected in changes in UCP3 levels, because the mitochondria will then be able to extract more esterified fatty acids from the cytoplasm, and the level of nonesterified fatty acids entering the mitochondria will drop. Patients suffering from riboflavin responsive multiple acylCoA dehydrogenase deficiency, a rare mitochondrial myopathy, are characterized by severely hampered fat oxidation and excessive muscular storage of lipids, which can be reversed partly by treatment with riboflavin. Untreated riboflavin responsive multiple acylCoA dehydrogenase deficiency patients show decreased oxidative capacity, excessive intramyocellular storage of lipids, and significant increases in UCP3 mRNA and protein (94). Treatment with riboflavin induced a return of fat oxidative capacity to control values and induced a significant drop in intramyocellular lipids. These notable changes in fat oxidation were accompanied by a return of UCP3 protein levels to control values (94). This indicates that restoration of fat oxidative capacity with simultaneous decline in fatty acid supply is followed by a rapid decline in UCP3 protein. Once more, this study supports the hypothesis that UCP3 exports fatty acid anions from the mitochondrial matrix.

Taken together, studies interfering in successive steps in fatty acid handling, transport, and oxidation consistently showed that UCP3 protein increases if the supply of fatty acids to the mitochondria exceeds fat oxidative capacity. Also, data are available indicating that the increased UCP3 levels can be normalized if fat oxidative capacity is enhanced. Although evidence that UCP3 is involved in fatty acid metabolism is compelling, none of the studies presented provide direct and definitive proof that UCP3 indeed facilitates outward translocation of fatty acids from the mitochondrial matrix as hypothesized before $(71,86)$.

\section{Conclusion}

Ever since cloning of the UCP1 homolog UCP3, studies have focused on identifying its primary physiological role. Based on knowledge derived from studies of UCP1, pioneering studies all focused on a putative role for UCP3 in energy expenditure. Cell and transgenic animal studies suggest that overexpression of UCP3 results in increased energy expenditure. It should be noted, however, that these results do not necessarily reflect human physiology, because it was shown in the cell and transgenic studies that the uncoupling observed was noninducible, as was anticipated given the observations in UCP1-expressing systems. Despite reports showing associations between the $U C P 3$ gene and markers for energy expenditure under a wide range of conditions, there are no compelling data unequivocally linking UCP3 to energy expenditure. The observation that fatty acid levels significantly affect UCP3 expression has given UCP3 a probable role in fatty acid handling and/or oxidation. Emerging data indicate that the primary physiological role of UCP3 may be the transport of fatty acid anions away from the mitochondrial matrix in exchange for a proton. The fatty acid anions exported may either originate from hydrolysis of fatty acid esters by an MTE1, or they may have entered the mitochondria as nonesterified fatty acids by incorporating into and flip-flopping across the mitochondrial innermembrane. If UCP3 indeed functions to export fatty acid anions from the mitochondrial matrix, it may have an important role in protecting mitochondria against the detrimental effects of high fatty acid levels. By doing so, UCP3 may help to maintain mitochondrial oxidative capacity and may be of importance in the prevention and/or treatment of obesity and diabetes. Clearly, future studies are needed to test these concepts and reconsider the role of UCP3 in obesity.

\section{Acknowledgments}

The authors thank Dr. G. J. van de Vusse for his encouraging data, which are pending publication while this article was prepared for submission. The research of P.S. has been made possible by fellowships of the Royal Netherlands Academy of Arts and Sciences and the Netherlands Organization for Scientific Research. The authors thank Dr. P. Frederik for preparation of the immnoelectron microscopy samples.

\section{References}

1. Mitchell P, Moyle J. Chemiosmotic hypothesis of oxidative phosphorylation. Nature. 1967;213:137-9.

2. Nicholls DG, Bernson VS, Heaton GM. The identification of the component in the inner membrane of brown adipose tissue mitochondria responsible for regulating energy dissipation. Experientia Suppl. 1978;32:89-93.

3. Rolfe DF, Brand MD. Contribution of mitochondrial proton leak to skeletal muscle respiration and to standard metabolic rate. Am J Physiol. 1996;271(4 Pt 1):C1380-9.

4. Rolfe DF, Newman JM, Buckingham JA, Clark MG, Brand MD. Contribution of mitochondrial proton leak to respiration rate in working skeletal muscle and liver and to SMR. Am J Physiol. 1999;276(3 Pt 1):C692-9.

5. Fleury C, Neverova M, Collins $\mathbf{S}$, et al. Uncoupling protein-2: a novel gene linked to obesity and hyperinsulinemia. Nat Genet. 1997;15:269-72.

6. Boss O, Samec S, Paoloni-Giacobino A, et al. Uncoupling protein-3: a new member of the mitochondrial carrier family with tissue-specific expression. FEBS Lett. 1997;408:39-42.

7. Nedergaard J, Matthias A, Golozoubova V, Jacobsson A, Cannon B. UCP1: the original uncoupling protein-and perhaps the only one? New perspectives on UCP1, UCP2, and UCP3 in the light of the bioenergetics of the UCP1-ablated mice. J Bioenerg Biomembr. 1999;31:475-91.

8. Gong DW, He Y, Karas M, Reitman M. Uncoupling protein-3 is a mediator of thermogenesis regulated by thyroid hormone, beta3-adrenergic agonists, and leptin. J Biol Chem. 1997;272:24129-32. 
9. Zhang CY, Hagen T, Mootha VK, Slieker LJ, Lowell BB. Assessment of uncoupling activity of uncoupling protein 3 using a yeast heterologous expression system. FEBS Lett. 1999;449:129-34.

10. Hinz W, Faller B, Gruninger S, Gazzotti P, Chiesi M. Recombinant human uncoupling protein-3 increases thermogenesis in yeast cells. FEBS Lett. 1999;448:57-61.

11. Hinz W, Gruninger S, De Pover A, Chiesi M. Properties of the human long and short isoforms of the uncoupling protein-3 expressed in yeast cells. FEBS Lett. 1999;462:411-5.

12. Stuart JA, Cadenas S, Jekabsons MB, Roussel D, Brand MD. Mitochondrial proton leak and the uncoupling protein 1 homologues. Biochim Biophys Acta. 2001;1504: $144-58$.

13. Stuart JA, Harper JA, Brindle KM, Jekabsons MB, Brand MD. A mitochondrial uncoupling artifact can be caused by expression of uncoupling protein 1 in yeast. Biochem J. 2001; 356(Pt 3):779-89.

14. Winkler E, Heidkaemper D, Klingenberg M, Liu Q, Caskey T. UCP3 expressed in yeast is primarily localized in extramitochondrial particles. Biochem Biophys Res Commun. 2001;282:334-40.

15. Clapham JC, Arch JR, Chapman H, et al. Mice overexpressing human uncoupling protein-3 in skeletal muscle are hyperphagic and lean. Nature. 2000;406:415-8.

16. Li B, Nolte LA, Ju JS, et al. Skeletal muscle respiratory uncoupling prevents diet-induced obesity and insulin resistance in mice. Nat Med. 2000;6:1115-20.

17. Cadenas S, Echtay KS, Harper JA, et al. The basal proton conductance of skeletal muscle mitochondria from transgenic mice overexpressing or lacking uncoupling protein-3. J Biol Chem. 2002;277:2773-8.

18. Echtay KS, Roussel D, St-Pierre J, et al. Superoxide activates mitochondrial uncoupling proteins. Nature. 2002;415: 96-9.

19. Schrauwen P, Schaart G, Saris WH, et al. The effect of weight reduction on skeletal muscle UCP2 and UCP3 mRNA expression and UCP3 protein content in type II diabetic subjects. Diabetologia. 2000;43:1408-16.

20. Hesselink MK, Keizer HA, Borghouts LB, et al. Protein expression of UCP3 differs between human type 1, type 2a, and type 2 b fibers. FASEB J. 2001;15:1071-3.

21. Harper JA, Stuart JA, Jekabsons MB, et al. Artifactual uncoupling by uncoupling protein 3 in yeast mitochondria at the concentrations found in mouse and rat skeletal-muscle mitochondria. Biochem J. 2002;361(Pt 1):49-56.

22. Gong DW, Monemdjou S, Gavrilova O, et al. Lack of obesity and normal response to fasting and thyroid hormone in mice lacking uncoupling protein-3. J Biol Chem. 2000;275: 16251-7.

23. Vidal-Puig AJ, Grujic D, Zhang CY, et al. Energy metabolism in uncoupling protein 3 gene knockout mice. $J$ Biol Chem. 2000;275:16258-66.

24. Jaburek M, Garlid KD. Reconstitution of recombinant uncoupling proteins-UCP1, 2, and 3 have similar affinities for ATP and are unaffected by coenzyme Q10. J Biol Chem. 2003;278:25825-31.
25. Cline GW, Vidal-Puig AJ, Dufour S, Cadman KS, Lowell BB, Shulman GI. In vivo effects of uncoupling protein-3 gene disruption on mitochondrial energy metabolism. $J$ Biol Chem. 2001;276:20240-4.

26. Ravussin E, Lillioja S, Knowler WC, et al. Reduced rate of energy expenditure as a risk factor for body-weight gain. N Engl J Med. 1988;318:467-72.

27. Schrauwen P, Xia J, Bogardus C, Pratley RE, Ravussin E. Skeletal muscle uncoupling protein 3 expression is a determinant of energy expenditure in Pima Indians. Diabetes. 1999; 48:146-9.

28. Hafner RP, Nobes CD, McGown AD, Brand MD. Altered relationship between protonmotive force and respiration rate in non-phosphorylating liver mitochondria isolated from rats of different thyroid hormone status. Eur J Biochem. 1988;178: 511-8.

29. Lanni A, Beneduce L, Lombardi A, et al. Expression of uncoupling protein-3 and mitochondrial activity in the transition from hypothyroid to hyperthyroid state in rat skeletal muscle. FEBS Lett. 1999;444:250-4.

30. de Lange P, Lanni A, Beneduce $\mathbf{L}$, et al. Uncoupling protein-3 is a molecular determinant for the regulation of resting metabolic rate by thyroid hormone. Endocrinology. 2001;142: 3414-20.

31. Jucker BM, Dufour S, Ren J, et al. Assessment of mitochondrial energy coupling in vivo by 13C/31P NMR. Proc Natl Acad Sci U S A. 2000;97:6880-4.

32. Lebon V, Dufour S, Petersen KF, et al. Effect of triiodothyronine on mitochondrial energy coupling in human skeletal muscle. J Clin Invest. 2001;108:733-7.

33. Jucker BM, Ren J, Dufour S, et al. 13C/31P NMR assessment of mitochondrial energy coupling in skeletal muscle of awake fed and fasted rats: relationship with uncoupling protein 3 expression. J Biol Chem. 2000;275:39279-86.

34. Hesselink MK, Greenhaff PL, Constantin-Teodosiu D, et al. Increased uncoupling protein 3 content does not affect mitochondrial function in human skeletal muscle in vivo. J Clin Invest. 2003;111:479-86.

35. Solanes G, Vidal-Puig A, Grujic D, Flier JS, Lowell BB. The human uncoupling protein-3 gene. Genomic structure, chromosomal localization, and genetic basis for short and long form transcripts. J Biol Chem. 1997;272:25433-6.

36. Halsall DJ, Luan J, Saker P, et al. Uncoupling protein 3 genetic variants in human obesity: the c-55t promoter polymorphism is negatively correlated with body mass index in a UK Caucasian population. Int J Obes Relat Metab Disord. 2001;25:472-7.

37. Otabe $\mathbf{S}$, Clement $\mathbf{K}$, Dina $\mathbf{C}$, et al. A genetic variation in the 5' flanking region of the UCP3 gene is associated with body mass index in humans in interaction with physical activity. Diabetologia. 2000;43:245-9.

38. Cassell PG, Saker PJ, Huxtable SJ, et al. Evidence that single nucleotide polymorphism in the uncoupling protein 3 (UCP3) gene influences fat distribution in women of European and Asian origin. Diabetologia. 2000;43:1558-64.

39. Dalgaard LT, Sorensen TI, Drivsholm T, et al. A prevalent polymorphism in the promoter of the UCP3 gene and its 
relationship to body mass index and long term body weight change in the Danish population. J Clin Endocrinol Metab. 2001;86:1398-402.

40. Dalgaard LT, Hansen T, Urhammer SA, Drivsholm T, Borch-Johnsen K, Pedersen O. The uncoupling protein 3-55 $\mathrm{C} \rightarrow \mathrm{T}$ variant is not associated with type II diabetes mellitus in Danish subjects. Diabetologia. 2001;44:1065-7.

41. Schrauwen P, Xia J, Walder K, Snitker S, Ravussin E. A novel polymorphism in the proximal UCP3 promoter region: effect on skeletal muscle UCP3 mRNA expression and obesity in male non-diabetic Pima Indians. Int J Obes Relat Metab Disord. 1999;23:1242-5.

42. Meirhaeghe A, Amouyel P, Helbecque N, et al. An uncoupling protein 3 gene polymorphism associated with a lower risk of developing type II diabetes and with atherogenic lipid profile in a French cohort. Diabetologia. 2000;43:1424-8.

43. Schrauwen P, Hesselink M. UCP2 and UCP3 in muscle controlling body metabolism. J Exp Biol. 2002;205(Pt 15): 2275-85.

44. Argyropoulos G, Brown AM, Willi SM, et al. Effects of mutations in the human uncoupling protein 3 gene on the respiratory quotient and fat oxidation in severe obesity and type 2 diabetes. J Clin Invest. 1998;102:1345-51.

45. Chung WK, Luke A, Cooper RS, et al. Genetic and physiologic analysis of the role of uncoupling protein 3 in human energy homeostasis. Diabetes. 1999;48:1890-5.

46. Urhammer SA, Dalgaard LT, Sorensen TI, et al. Organisation of the coding exons and mutational screening of the uncoupling protein 3 gene in subjects with juvenile-onset obesity. Diabetologia. 1998;41:241-4.

47. Astrup A, Bulow J, Madsen J, Christensen NJ. Contribution of BAT and skeletal muscle to thermogenesis induced by ephedrine in man. Am J Physiol. 1985;248(5 Pt 1):E507-15.

48. Simonsen L, Bulow J, Madsen J, Christensen NJ. Thermogenic response to epinephrine in the forearm and abdominal subcutaneous adipose tissue. Am J Physiol. 1992;263(5 Pt 1):E850-5.

49. Nakamura Y, Nagase I, Asano A, et al. Beta 3-adrenergic agonist up-regulates uncoupling proteins 2 and 3 in skeletal muscle of the mouse. J Vet Med Sci. 2001;63:309-14.

50. Gomez-Ambrosi J, Fruhbeck G, Martinez JA. Leptin, but not a beta 3-adrenergic agonist, up-regulates muscle uncoupling protein-3 messenger RNA expression: short-term thermogenic interactions. Cell Mol Life Sci. 1999;55:992-7.

51. Nagase I, Yoshida T, Saito M. Up-regulation of uncoupling proteins by beta-adrenergic stimulation in L6 myotubes. FEBS Lett. 2001;494:175-80.

52. Hoeks J, Van Baak MA, Hesselink MK, et al. Effect of $\beta 1$ and $\beta 2$-adrenergic stimulation on energy expenditure, substrate oxidation, and UCP3 expression in humans. Am J Physiol Endocrinol Metab. 2003;285:E775-82.

53. Millet L, Vidal H, Andreelli F, et al. Increased uncoupling protein-2 and -3 mRNA expression during fasting in obese and lean humans. J Clin Invest. 1997;100:2665-70.

54. Boss O, Samec S, Kuhne F, et al. Uncoupling protein-3 expression in rodent skeletal muscle is modulated by food intake but not by changes in environmental temperature. J Biol Chem. 1998;273:5-8.
55. Weigle DS, Selfridge LE, Schwartz MW, et al. Elevated free fatty acids induce uncoupling protein 3 expression in muscle: a potential explanation for the effect of fasting. Diabetes. 1998;47:298-302.

56. Hwang CS, Lane MD. Up-regulation of uncoupling protein-3 by fatty acid in $\mathrm{C} 2 \mathrm{C} 12$ myotubes. Biochem Biophys Res Commun. 1999;258:464-9.

57. Brun S, Carmona MC, Mampel T, et al. Uncoupling protein-3 gene expression in skeletal muscle during development is regulated by nutritional factors that alter circulating nonesterified fatty acids. FEBS Lett. 1999;453:205-9.

58. Bezaire V, Hofmann W, Kramer JK, Kozak LP, Harper ME. Effects of fasting on muscle mitochondrial energetics and fatty acid metabolism in Ucp3(-/-) and wild-type mice. Am J Physiol Endocrinol Metab. 2001;281:E975-82.

59. Zurlo F, Lillioja S, Esposito-Del Puente A, et al. Low ratio of fat to carbohydrate oxidation as predictor of weight gain: study of 24-h RQ. Am J Physiol. 1990;259(5 Pt 1):E650-7.

60. Brun S, Carmona MC, Mampel T, et al. Activators of peroxisome proliferator-activated receptor-alpha induce the expression of the uncoupling protein-3 gene in skeletal muscle: a potential mechanism for the lipid intake-dependent activation of uncoupling protein-3 gene expression at birth. Diabetes. 1999;48:1217-22.

61. Samec S, Seydoux J, Dulloo AG. Post-starvation gene expression of skeletal muscle uncoupling protein 2 and uncoupling protein 3 in response to dietary fat levels and fatty acid composition: a link with insulin resistance. Diabetes. 1999; 48:436-41.

62. Chou CJ, Cha MC, Jung DW, Boozer CN, Hashim SA, Pi-Sunyer FX. High-fat diet feeding elevates skeletal muscle uncoupling protein 3 levels but not its activity in rats. Obes Res. 2001;9:313-9.

63. Schrauwen P, Hoppeler H, Billeter R, Bakker A, Pendergast $\mathbf{D}$. Fiber type dependent up-regulation of human skeletal muscle UCP2 and UCP3 mRNA expression by high-fat diet. Int J Obes Relat Metab Disord. 2001;25:449-56.

64. Cameron-Smith D, Burke LM, Angus DJ, et al. A shortterm, high-fat diet up-regulates lipid metabolism and gene expression in human skeletal muscle. Am J Clin Nutr. 2003; 77:313-8.

65. Cortright RN, Zheng D, Jones JP, et al. Regulation of skeletal muscle UCP-2 and UCP-3 gene expression by exercise and denervation. Am J Physiol. 1999;276(1 Pt 1):E21721.

66. Zhou M, Lin BZ, Coughlin S, Vallega G, Pilch PF. UCP-3 expression in skeletal muscle: effects of exercise, hypoxia, and AMP-activated protein kinase. Am J Physiol Endocrinol Metab. 2000;279:E622-9.

67. Pilegaard H, Ordway GA, Saltin B, Neufer PD. Transcriptional regulation of gene expression in human skeletal muscle during recovery from exercise. Am J Physiol Endocrinol Metab. 2000;279:E806-14.

68. Boss O, Samec S, Desplanches D, et al. Effect of endurance training on mRNA expression of uncoupling proteins 1, 2, and 3 in the rat. FASEB J. 1998;12:335-9. 
69. Schrauwen P, Troost FJ, Xia J, Ravussin E, Saris WH. Skeletal muscle UCP2 and UCP3 expression in trained and untrained male subjects. Int J Obes Relat Metab Disord. 1999;23:966-72.

70. Russell AP, Wadley G, Hesselink MKC, et al. UCP3 protein expression is lower in type I, IIa and IIx muscle fiber types of endurance-trained compared to untrained subjects. Pflugers Arch. 2003;445:563-9.

71. Schrauwen P, Saris WH, Hesselink MK. An alternative function for human uncoupling protein 3: protection of mitochondria against accumulation of nonesterified fatty acids inside the mitochondrial matrix. FASEB J. 2001;15:2497-502.

72. Hjeltnes N, Fernstrom M, Zierath JR, Krook A. Regulation of UCP2 and UCP3 by muscle disuse and physical activity in tetraplegic subjects. Diabetologia. 1999;42:826-30.

73. Schrauwen P, Hesselink MK, Vaartjes I, et al. Effect of acute exercise on uncoupling protein 3 is a fat metabolismmediated effect. Am J Physiol Endocrinol Metab. 2002;282: E11-7.

74. Hildebrandt AL, Neufer PD. Exercise attenuates the fastinginduced transcriptional activation of metabolic genes in skeletal muscle. Am J Physiol Endocrinol Metab. 2000;278: E1078-86.

75. Baarends EM, Schols AM, Akkermans MA, Wouters EF. Decreased mechanical efficiency in clinically stable patients with COPD. Thorax. 1997;52:981-6.

76. Gosker HR, Schrauwen P, Hesselink MK, et al. Uncoupling protein-3 content is decreased in peripheral skeletal muscle of patients with COPD. Eur Respir J. 2003;22:88-93.

77. Samec S, Seydoux J, Dulloo AG. Role of UCP homologues in skeletal muscles and brown adipose tissue: mediators of thermogenesis or regulators of lipids as fuel substrate? FASEB J. 1998;12:715-24.

78. Samec S, Seydoux J, Dulloo AG. Interorgan signaling between adipose tissue metabolism and skeletal muscle uncoupling protein homologs: is there a role for circulating free fatty acids? Diabetes. 1998;47:1693-8.

79. Schrauwen P, Wagenmakers AJ, van Marken Lichtenbelt WD, Saris WH, Westerterp KR. Increase in fat oxidation on a high-fat diet is accompanied by an increase in triglyceridederived fatty acid oxidation. Diabetes. 2000;49:640-6.

80. Mingrone G, Rosa G, Greco AV, et al. Decreased uncoupling protein expression and intramyocytic triglyceride depletion in formerly obese subjects. Obes Res. 2003;11:632-40.

81. Hidaka S, Kakuma T, Yoshimatsu H, Sakino H, Fukuchi S, Sakata T. Streptozotocin treatment up-regulates uncoupling protein 3 expression in the rat heart. Diabetes. 1999;48: $430-5$.
82. Hidaka S, Yoshimatsu H, Kakuma T, et al. Tissue-specific expression of the uncoupling protein family in streptozotocininduced diabetic rats. Proc Soc Exp Biol Med. 2000;224: $172-7$.

83. Hamilton JA, Kamp F. How are free fatty acids transported in membranes? Is it by proteins or by free diffusion through the lipids? Diabetes. 1999;48:2255-69.

84. Jezek P, Engstova H, Zackova M, et al. Fatty acid cycling mechanism and mitochondrial uncoupling proteins. Biochim Biophys Acta. 1998;1365:319-27.

85. Skulachev VP. Anion carriers in fatty acid-mediated physiological uncoupling. J Bioenerg Biomembr. 1999;31:431-45.

86. Himms-Hagen J, Harper ME. Physiological role of UCP3 may be export of fatty acids from mitochondria when fatty acid oxidation predominates: an hypothesis. Exp Biol Med (Maywood). 2001;226:78-84.

87. Moore GB, Himms-Hagen J, Harper ME, Clapham JC. Overexpression of UCP-3 in skeletal muscle of mice results in increased expression of mitochondrial thioesterase mRNA. Biochem Biophys Res Commun. 2001;283:785-90.

88. Clapham JC, Coulthard VH, Moore GB. Concordant mRNA expression of UCP-3, but not UCP-2, with mitochondrial thioesterase-1 in brown adipose tissue and skeletal muscle in $\mathrm{db} / \mathrm{db}$ diabetic mice. Biochem Biophys Res Commun. 2001;287:1058-62.

89. Lanni A, Mancini F, Sabatino L, et al. De novo expression of uncoupling protein 3 is associated to enhanced mitochondrial thioesterase- 1 expression and fatty acid metabolism in liver of fenofibrate-treated rats. FEBS Lett. 2002;525:7-12.

90. Acin A, Rodriguez M, Rique H, Canet E, Boutin JA, Galizzi JP. Cloning and characterization of the 5' flanking region of the human uncoupling protein 3 (UCP3) gene. Biochem Biophys Res Commun. 1999;258:278-83.

91. Silva JE, Rabelo R. Regulation of the uncoupling protein gene expression. Eur J Endocrinol. 1997;136:251-64.

92. Hunt MC, Nousiainen SE, Huttunen MK, Orii KE, Svensson LT, Alexson SE. Peroxisome proliferator-induced long chain acyl-CoA thioesterases comprise a highly conserved novel multi-gene family involved in lipid metabolism. $J$ Biol Chem. 1999;274:34317-26.

93. Schrauwen P, Hinderling V, Hesselink MK, et al. Etomoxir-induced increase in UCP3 supports a role of uncoupling protein 3 as a mitochondrial fatty acid anion exporter. FASEB J. 2002;16:1688-90.

94. Russell AP, Schrauwen P, Somm E, et al. Decreased fatty acid $\beta$-oxidation in riboflavin-responsive multiple acylCoA dehydrogenase deficient patients is associated with an increase in UCP3. J Clin Endocrinol Metab. 2003. (in press). 